\title{
Customised growth charts in large-for-gestational-age infants and the association with emergency caesarean section rate.
}

Doctor Natasha PRITCHARD ${ }^{1,2}$

MBBS, MRMed

Registrar, The Royal Australian New Zealand College of Obstetricians and

Gynaecologists

Email: natasha.pritchard@trainee.ranzcog.edu.au

Address: 163 Studley Road, HEIDELBERG 3081

Phone: 0384587777

\section{Doctor Anthea LINDQUIST ${ }^{1,2}$}

FRANZCOG, PhD, MBBS

Consultant Obstetrician and Gynaecologist, Mercy Hospital for Women.

Email: aclin123@gmail.com

\section{Doctor Richard HISCOCK ${ }^{1}$}

FANZCA, MBBS, MBiostat

Consultant, Mercy Hospital for Women.

Email: richardjhiscock@gmail.com

\section{Doctor Prenna DIKSHA ${ }^{1,4}$}

MD, BBMed

Junior Doctor, St Vincent's Hospital Melbourne

Email: prerna.diksha@gmail.com

\section{Professor Susan P WALKER ${ }^{1,2}$}

FRANZCOG, MD, CMFM

Professor of Maternal Fetal Medicine, University of Melbourne

Email: spwalker@unimelb.edu.au

This is the author manuscript accepted for publication and has undergone full peer review but has not been through the copyediting, typesetting, pagination and proofreading process, which may lead to differences between this version and the Version of Record. Please cite this article as doi: 10.1111/ajo.12868

This article is protected by copyright. All rights reserved 


\section{Professor Michael PERMEZEL ${ }^{1,2}$}

FRANZCOG, MD, MBBS

Professor of Obstetrics and Gynaecology, University of Melbourne

Email: m.permezel@unimelb.edu.au

\section{Institutional Affiliations:}

${ }^{1}$ Department of Obstetrics and Gynaecology, Faculty of Medicine, University of Melbourne, Parkville, Victoria, Australia

${ }^{2}$ Department of Obstetrics and Gynaecology, Mercy Hospital for Women, Heidelberg, Victoria, Australia

${ }^{3}$ Department of Medicine, St Vincent's Hospital Melbourne, Fitzroy, Victoria, Australia

\section{Financial disclosures:}

Author NP is supported by a NHMRC postgraduate research scholarship, the RANZCOG Arthur Wilson Memorial scholarship, and a MIGA grant.

\section{Acknowledgements:}

The authors would like to thank the Mercy Hospital for Women's Medical Records Department, particularly Ms Tania Fletcher, for their assistance with data collection

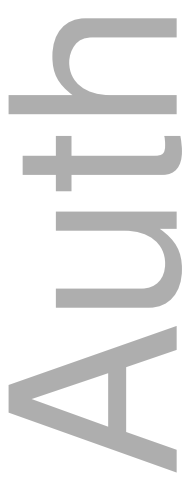


DR. NATASHA PRITCHARD (Orcid ID : 0000-0002-7388-2193)

Article type : Original Manuscript

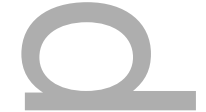

(19.20

Customised growth charts in large-for-gestational-age infants and the association with emergency caesarean section rate.

Short title: Customised centiles in the large-for-gestational-age infant.

Word count (abstract): 249

Word count (main text):

ABSTRACT

Background and Aim:

Large-for-gestational age (LGA) infants are at increased risk of intrapartum complications. However, some infants classified as LGA may be appropriate-forgestational age (AGA) if adjusted for maternal stature. We determined whether customisation of birthweight centiles by maternal height, or height and weight, improves the detection of LGA infants at risk of complications.

Methods:

We conducted a retrospective analysis of 38,246 term, singleton nulliparous women. We compared population birthweight centiles to those customised by height, or height and weight for complications including intrapartum caesarean section, instrumental delivery, postpartum haemorrhage, anal sphincter injury and neonatal outcomes.

Results:

This article is protected by copyright. All rights reserved 
Those considered LGA when customised for height but AGA by population centiles (LGA-ht-only) were at increased risk of intrapartum emergency caesarean section compared with infants AGA on all charts (AGA-all); OR 4.64, 95\%CI 3.22-6.76. In contrast, infants considered LGA on population charts, but AGA when customised by height (LGA-pop-only) were not at increased risk compared to the AGA-all group (OR 1.43, 95\%CI 0.70-1.88). Infants classified as LGA-ht-only compared to LGApop-only remained at significantly higher risk after adjustment for potential confounders (aOR 3.27; 95\% CI 2.02-5.31). No difference was seen for any other outcomes. No benefit was seen with customisation by both maternal height and weight.

\section{Conclusion:}

Women with an infant classified as AGA on population centiles but LGA when customised for height are at increased risk of intrapartum caesarean section. This is a population unrecognised in current practice. Fetal growth should be customised for maternal height when making assessments regarding the LGA infant.

\section{INTRODUCTION}

There are many intrapartum risks associated with babies that are large for gestational age (LGA). For the infant, difficulties passing through the bony maternal pelvis can lead to shoulder dystocia and associated birth asphyxia. For the mother, labour can be prolonged or associated with complications such as postpartum haemorrhage and soft tissue injury, including third and fourth degree perineal tears. Ultimately, the infant may simply be too large to fit through the pelvis, leading to obstructed labour and increased risks of emergency caesarean section. ${ }^{1-7}$

In 2015, Boulvain et al published a multi-centre randomised controlled trial which demonstrated an increase in spontaneous vaginal delivery rate and a reduction in clinically significant shoulder dystocia if women with a suspected macrosomic fetus (>95th centile at a 36-38 week ultrasound) were induced between $37+0$ and $38+6$ weeks gestation. ${ }^{8,9}$ In many obstetric units internationally, this has led to an increase in elective inductions at term for this indication. However, as with small for 
gestational age (SGA) infants, not every LGA infant is inappropriately grown, and some may be considered appropriate for gestational age when adjusted for maternal stature. If it were possible to identify which LGA fetuses were at greatest risk, it would be easier to tailor obstetric intervention to those most likely to benefit.

Using customised fetal growth centiles has been shown to improve detection of LGA infants at greatest risk of intrapartum complications such as operative delivery and shoulder dystocia and have shown stronger relationships with perinatal morbidity and mortality. ${ }^{10-12}$ Customisation adjusts for both maternal height and weight, as well as other factors, but to date no studies have determined whether customisation by maternal height alone, or alternatively both height and weight, better predicts the risk of adverse outcomes in labour among LGA infants. Increasing maternal weight is typically associated with increasing birthweight, yet in the absence of an accompanying increase in pelvic diameters. Customisation of LGA infants by both maternal height and weight may therefore artificially normalise the fetal size, and underestimate the risk of obstructed labour and intrapartum caesarean section. In contrast, customisation by maternal height alone, may better identify the disproportionately large fetus at increased risk of obstruction and caesarean section, ie. a taller woman may have greater pelvic capacity for what is a constitutionally large fetus, compared to a shorter woman carrying a disproportionately large fetus.

Using the primary outcome of emergency caesarean section in labour, this study aimed to assess i) whether customisation of birthweight centiles by maternal height, compared with uncustomised population birthweight centiles, improves the prediction of the LGA infant at risk of intrapartum caesarean section, and ii) whether customisation by maternal height alone is preferable to customisation by both maternal height and weight.

\section{METHODS}

Study population and data collection:

A retrospective population cohort study was conducted on all term, nulliparous women who delivered from 1994 to 2016 at the Mercy Hospital for Women (MHW) 
in Melbourne, Victoria, a tertiary obstetric centre. Data for all women giving birth at MHW is recorded by midwives on the Birthing Outcomes System (BOS) and all data included in the study was extracted from this database.

Women were considered term from 37.0 to 42.0 weeks' gestation at delivery. Height and weight used in this analysis was the earliest recorded height or weight taken at the obstetric booking visit for each woman. Women were excluded from all analyses if data on the maternal height or weight, gestation or birthweight was missing.

\section{Customised centile groups:}

Gestation Related Optimal Weight (GROW) centiles were used for customised standards (version 6.7.8, 2017), which incorporated data up to 2015 and used coefficients developed and validated previously by Gardosi et al. ${ }^{13}$ The baseline birthweight centiles are derived from Australian population birthweight statistics, and are provided for each completed day of gestation. The GROW charts provide the option of customisation by multiple maternal characteristics including maternal height, weight ethnic origin, parity and infant sex. If a variable was not customised for, standard average values were then used by default. These included a maternal weight of $64.3 \mathrm{~kg}$, ethnic origin of European Australian and infant sex neutral. We calculated three centiles for the birthweight of each neonate in the study; 1) an uncustomised birthweight centile 2) a birthweight centile customised only for maternal height, and 3) a birthweight centile customised for both maternal height and weight.

Infants were classified as LGA $(\geq 90$ th centile $)$ or AGA $\left(<90^{\text {th }}\right.$ centile $)$ for each birthweight classification chart, ie. LGA-pop, LGA-ht, LGA-ht+wt. The group of women that were AGA by all charts (AGA-all) were used as a baseline low-risk comparison given that they were not LGA by any definition used in this study.

Of most interest were those infants classified as LGA by one definition but not by another, as follows:

a) LGA when customised for height but AGA on population charts (LGA-htonly; i.e. 'missed' by current population charts but identified as LGA on height-customised charts). This group includes infants considered average by 
population standards, but when the mother's short stature was accounted for, the infant was considered LGA.

b) LGA on population charts but AGA on height-customised charts (LGA-poponly; i.e. those 'missed' on customised charts but identified as LGA on current population charts). This group includes infants considered large by population standards, but when accounting for the mother's tall height, were considered appropriately grown.

Similar comparisons were performed for height-customised versus both height \& weight-customised charts. The comparison between groups of infants who were identified exclusively on one chart enabled a quantification of the risk of adverse outcome amongst those overlooked under each alternative method.

\section{Outcomes:}

The primary outcome was intrapartum caesarean section rate, defined as the proportion of women who were delivered by unplanned emergency caesarean section. Women who had an elective caesarean section were excluded from analysis. Secondary maternal outcomes included the rates of instrumental birth, severe perineal trauma (third or fourth degree tears) and massive post-partum haemorrhage (PPH) ( $\geq 1000 \mathrm{mls}$ loss). Secondary neonatal outcomes included Apgars $<7$ at five minutes, shoulder dystocia, and admission to the Special Care Nursery (SCN) or Neonatal Intensive Care Unit (NICU).

\section{Statistical analysis:}

Statistical analysis was conducted using GraphPad Prism Version 7 and Stata statistical software (StataCorp, 2017. Stata Statistical Software: Release 15. Stata Corp LP. College Station, TX).

Means, standard deviations, medians and percentages of the total study population were used to describe baseline characteristics. Chi-square tests and odds ratios were used to determine the significance of the associations between categorical variables. Multivariate logistic regression analysis was used to further assess the odds of emergency caesarean section, adjusted for gestation, maternal age and BMI. P-values $<0.05$ were considered statistically significant. 
Ethics Approval:

Ethics approval for the project was obtained from the Mercy Hospital for Women Human Research Ethics Committee (approval project number R16-61).

\section{RESULTS}

From 1994 to 2016, there were 38,246 term, nulliparous women with a singleton pregnancy identified through the hospital's obstetric database. Centile charts were applied to all study participants and 35,854 (93.7\%) were considered AGA by all charts (AGA-all). LGA by population birthweight charts (LGA-Pop) identified 1,917 (5\%) infants, LGA customised by height (LGA-Ht) identified 1,754 (4.6\%) infants, and LGA by charts customised on height and weight (LGA-Ht+Wt) identified 1,904 $(5.0 \%)$ infants.

Comparison between population birthweight centiles and heightcustomised centiles

Of the 1,917 women considered LGA by population charts, 1627 were LGA on both charts while 290 (15.1\%) were considered AGA when customised for maternal height (LGA-pop-only). Of the 1,754 women considered LGA by charts customised by height, 127 (7.2\%) were considered AGA on population charts (LGA-ht only) (Figure 1). The difference attributable to maternal height can be seen in Table 1, with infants classified as LGA-pop-only coming from taller mothers (mean height of $174 \mathrm{~cm}$ ), compared with infants classified as LGA-ht-only coming from shorter mothers (mean height of $156 \mathrm{~cm})$.

Overall, infants classified as LGA, by population or height customised birthweight centiles, were at significantly increased risk of emergency caesarean section than the infant that was AGA on all charts (AGA-all) (Table II). Compared with AGA-all infants, LGA-ht-only infants were at greater risk for emergency caesarean section (OR 4.64; 95\%CI 3.22-6.76), but LGA-pop-only infants were not (OR 1.43; 95\%CI 0.70-1.88). 
Multivariate analysis, adjusting for age, gestation and BMI, was performed to compare the sub-groups identified by only one chart. Infants considered LGA-ht-only remained at significantly higher odds of an emergency caesarean section than LGApop-only after adjustment for potential confounders (aOR 3.27; 95\%CI 2.02-5.31).

Comparison between the two main sub-groups of interest, LGA-pop-only and LGAht-only, revealed a small difference in absolute mean birthweight (4015g vs 4140g, $\mathrm{p}<0.001$ ) (Table 1). Consistent with the increase in emergency caesarean section rate, there was a higher rate of caesarean section birth overall in the LGA-ht-only group compared to the LGA-pop-only group $(34.5 \%$ vs $61.4 \%$, p<0.001). There was no difference in incidence of instrumental vaginal birth between the groups. No significant differences were seen in any adverse neonatal outcomes, although there was a trend towards higher rates of low Apgars $<7(1.6 \%$ vs $0.0 \%, \mathrm{p}=0.092)$ and shoulder dystocia $(10.2 \%$ vs $4.2 \%, \mathrm{p}=0.068)$ in the LGA-ht-only group. Similarly, there were trends towards increased rates of massive $\mathrm{PPH}>1 \mathrm{~L}$ and $3^{\text {rd }} / 4^{\text {th }}$ degree tears but these also did not reach statistical significance.

Comparison between height-customised charts with height and weightcustomised charts

Of the 1,904 infants identified as LGA based on height and weight-customised charts, $413(21.6 \%)$ were considered LGA based solely on height and weight-customised charts (LGA-ht+wt only). Of the 1,754 infants considered LGA by height-customised charts, $263(15.0 \%)$ were considered LGA by height-customised charts only (LGA-htonly) (Figure 2).

Customisation by height and weight in the LGA-ht-plus-wt group enables taller and heavier women to have a larger infant classified as AGA. Accordingly, those classified as LGA-ht-only but AGA-ht+wt were heavier with a mean BMI of 34.1 (Table 3), while infants classified as LGA-ht+wt-only had a mean BMI of 21.4. These were infants considered appropriately grown when maternal height only was considered, but LGA when customised for her (lower) bodyweight. 
There were significant differences in baseline birthweight, with larger birthweight identified in the LGA-ht-only group (4144 vs 4001g, p<0.001). Again, women with LGA infants customised on maternal height only, had a higher rate of emergency caesarean section than those customised on both height and weight (OR 1.85, 95\% CI $1.32-2.61,47.8 \%$ vs $33.1 \%$, p<0.001).

Comparison between height and weight-customised charts and uncustomised population charts

Of the 1,904 infants classified as LGA based on height and weight-customised charts, $440(23.1 \%)$ were considered AGA by population charts (LGA-ht+wt-only). Of the 1,917 infants considered LGA by population charts, 453 (23.6\%) were only considered LGA by population charts (LGA-pop-only) (Figure II). 1491 infants were considered LGA by both height and height and weight customisation. The LGA-poponly group included infants whose mothers were either tall, had a heavy weight, or a combination of both, as the infants were considered average weight after customisation. The LGA-ht+wt-only group were the inverse, with either short maternal stature or low weight, or a combination of both. Unsurprisingly, BMI and birthweight were both higher in the LGA-pop-only (AGA-ht+wt-only) compared to the LGA-ht+wt-only (AGA-pop-only). There were no significant differences between these two groups in emergency caesarean section rate (OR 1.06, 95\% CI 0.80 to 1.41 ), overall chance of having a vaginal birth, or instrumental birth rate (Table III).

\section{DISCUSSION}

\section{Summary of findings:}

Customisation of fetal weight by maternal height has a twofold benefit. Firstly, we have identified that these LGA-ht only infants are at increased risk of intrapartum caesarean section, even though they are considered AGA on uncustomised population-based birthweight centiles. These LGA-ht-only pregnancies are not currently identified using population centiles, and this group might represent a more targeted group likely to benefit from obstetric intervention, such as induction for macrosomia. Secondly, it identifies the group of fetuses (AGA-ht-only, LGA-pop) that do not appear to be at higher risk of emergency caesarean section or other adverse 
outcomes than an AGA infant. These large infants of tall mothers have no increase in Caesarean section risk and so reclassification as AGA could reduce unnecessary induction of labour. These findings remained significant after adjustment for maternal age, BMI and gestation at delivery. These findings were also irrespective of absolute birthweight, which was lower in the high-risk group identified only by maternal height.

We did not find that customisation by maternal height and weight added any benefit in comparison to an uncustomised, population chart, and was clearly inferior to charts customised on maternal height alone. This suggests that in the case of macrosomia, making additional allowance for maternal weight will artificially normalise fetal size in the setting of maternal obesity, yet these women may not have a corresponding increase in skeletal size, particularly of the maternal pelvis. This contrasts with customisation by height, where delivery of a larger fetus to a taller mother will to some extent be assisted by a corresponding increase in pelvic dimensions. With the rising prevalence in obesity worldwide, and the associated rise in fetal macrosomia, it is important to identify accurately which LGA populations are at higher risk of intrapartum complications and who may benefit most from timely intervention.

Our findings are consistent with the growing body of literature reinforcing the importance of accounting for maternal characteristics in determining optimal fetal weight. Larkin et al. in 2011 found that those identified as LGA by customised standards, even if not macrosomic using an absolute birthweight cut-off, or LGA by population standards, were at increased risk of shoulder dystocia. ${ }^{12}$ Pasupathy et al also found that the group considered LGA by population standards, if AGA by customised charts, were not at increased risk of adverse outcomes. ${ }^{10}$ More recently, Gonzales et al. ${ }^{14}$ also found benefit of customised centiles in a diabetic antenatal population, when assessing for macrosomia.

What studies to date have not teased out is which maternal characteristics contribute most to the observed benefit of customisation. Our study is the first to directly compare the differences between customisation by maternal height, or both maternal height and weight. While height and weight are routinely included in customisation, this study suggests that adjusting for maternal weight may be less beneficial in 
assessment of the LGA infant. This contrasts with assessment of the small fetus. Obesity is a known risk factor for placental dysfunction, small for gestational age (SGA) and stillbirth. ${ }^{15}$ Customisation for maternal height and weight will identify more infants of bigger mothers as being SGA and these are more likely to be pathologically growth restricted. While customisation by both maternal height and weight may be beneficial in these circumstances, the opposite is true when assessing excessive fetal growth.

\section{$\underline{\text { Strengths and limitations: }}$}

This study provides a unique analysis of the benefits of customisation on maternal factors in the detection of the LGA infant. Specifically, this study demonstrates which LGA infants are most at risk of emergency caesarean section. This may inform clinical practice. By optimising detection of the LGA group at highest risk of obstructed labour and intrapartum caesarean birth, resources can be directed toward the group of women who may benefit most from induction for macrosomia. Potentially, this could in turn reduce the health and economic burden associated with unnecessary induction of labour and reduce the rate of emergency caesarean sections.

An inherent difficulty in comparing different growth charts is the large degree of overlap. As the differences with customisation can be subtle, most infants will be considered LGA by more than one chart. This means that very large sample sizes are required to achieve sufficient power to detect a difference. By comparing subgroups identified by only one chart, we were able to differentiate between customised and population charts. Infants classified as LGA on all charts are at unequivocally increased risk already, and do not require further study.

Our study excluded multiparous women, and as such may not be generalizable to that population. However, in subsequent pregnancies, clinical delivery decisions are significantly informed by whether a vaginal birth has previously been achieved. This is a different scenario than in the setting of the 'untried' pelvis and counselling can be more individualised. This study did not customise for ethnicity. Although 'country of birth' was available for most women, extrapolating to ethnicity can be unreliable, especially given the high level of immigration in Australia.9,14 
We were unable to reliably capture conditions more likely to be associated with pathological macrosomia, particularly gestational and pre-existing diabetes, which is likely to be of higher prevalence in groups with increased BMI. However, there is already substantial evidence demonstrating that the anthropometry of infants of diabetic mothers makes them at increased risk of intrapartum complications. ${ }^{3}$ This should already be incorporated into the clinical decision making process. It is possible that growth restricted infants, on the opposite end of the spectrum, may also be at increased risk of emergency caesarean section. These were included within our comparison group of $<90^{\text {th }}$ centile, and may have led to an underestimation of the difference between the LGA infant, and the appropriately grown one.

\section{Conclusion:}

This study demonstrates that height-customised charts, but not height and weightcustomised charts, improve the prediction of emergency caesarean section associated with the LGA infant. By identifying a high-risk subgroup currently unrecognised on uncustomised, population charts, and by excluding a low-risk subgroup that is not at increased risk of caesarean section, use of height-customised charts provides the opportunity for more accurately targeted obstetric intervention. Consideration should be given to validation of height-adjusted charts in external populations, and to introduction of these birthweight standards into clinical practice.

\section{References}

1. Boulet SL, Alexander GR, Salihu HM, Pass M. Macrosomic births in the united states: Determinants, outcomes, and proposed grades of risk. American Journal of Obstetrics and Gynecology. 2003;188(5):1372-1378.

2. Boulet SL, Salihu HM, Alexander GR. Mode of delivery and birth outcomes of macrosomic infants. Journal of Obstetrics and Gynaecology. 2004;24(6):622-629.

3. Esakoff TF, Cheng YW, Sparks TN, Caughey AB. The association between birthweight $4000 \mathrm{~g}$ or greater and perinatal outcomes in patients with and without gestational diabetes mellitus. Am J Obstet Gynecol. 2009;200(6):672.e671-674. 
4. Jolly MC, Sebire NJ, Harris JP, Regan L, Robinson S. Risk factors for macrosomia and its clinical consequences: a study of 350,311 pregnancies. European Journal of Obstetrics \& Gynecology and Reproductive Biology. 2003;111(1):9-14.

5. Stotland NE, Caughey AB, Breed EM, Escobar GJ. Risk factors and obstetric complications associated with macrosomia. International Journal of Gynecology \& Obstetrics. 2004;87(3):220-226.

6. Mulik V, Usha Kiran TS, Bethal J, Bhal PS. The outcome of macrosomic fetuses in a low risk primigravid population. International Journal of Gynecology \& Obstetrics. 2003;80(1):15-22.

7. Raio L, Ghezzi F, Di Naro E, et al. Perinatal outcome of fetuses with a birth weight greater than $4500 \mathrm{~g}$ : an analysis of 3356 cases. Eur J Obstet Gynecol Reprod Biol. 2003;109(2):160-165.

8. Boulvain M, Senat MV, Perrotin F, et al. Induction of labour versus expectant management for large-for-date fetuses: a randomised controlled trial. Lancet. 2015;385(9987):2600-2605.

9. Boulvain M, Irion O, Dowswell T, Thornton JG. Induction of labour at or near term for suspected fetal macrosomia. Cochrane Database Syst Rev. 2016(5):Cd000938.

10. Pasupathy D, McCowan LM, Poston L, Kenny LC, Dekker GA, North RA. Perinatal outcomes in large infants using customised birthweight centiles and conventional measures of high birthweight. Paediatr Perinat Epidemiol. 2012;26(6):543-552.

11. Cha HH, Kim JY, Choi SJ, Oh SY, Roh CR, Kim JH. Can a customized standard for large for gestational age identify women at risk of operative delivery and shoulder dystocia? J Perinat Med. 2012;40(5):483-488.

12. Larkin JC, Speer PD, Simhan HN. A customized standard of large size for gestational age to predict intrapartum morbidity. Am J Obstet Gynecol. 2011;204(6):499.e491-410.

13. Mongelli M, Figueras F, Francis A, Gardosi J. A customized birthweight centile calculator developed for an Australian population. The Australian \& New Zealand journal of obstetrics \& gynaecology. 2007;47(2):128-131. 
14. González González NL, Plasencia W, González Dávila E, et al. The effect of customized growth charts on the identification of large for gestational age newborns. The Journal of Maternal-Fetal \& Neonatal Medicine. 2013;26(1):62-65.

15. Marchi J, Berg M, Dencker A, Olander EK, Begley C. Risks associated with obesity in pregnancy, for the mother and baby: a systematic review of reviews. Obesity Reviews. 2015;16(8):621-638.

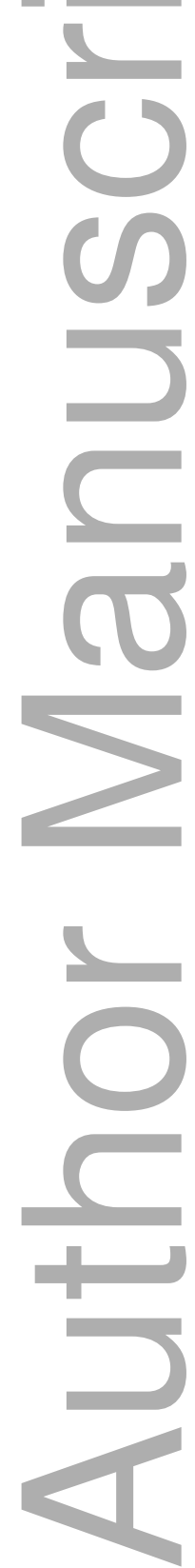

This article is protected by copyright. All rights reserved 
Figure I: Comparison of height-customised charts with uncustomised population charts. Number of women identified by both charts (LGApop+LGA-ht), a population chart only (LGA-pop-only) or height-customised charts only (LGA-ht-only).

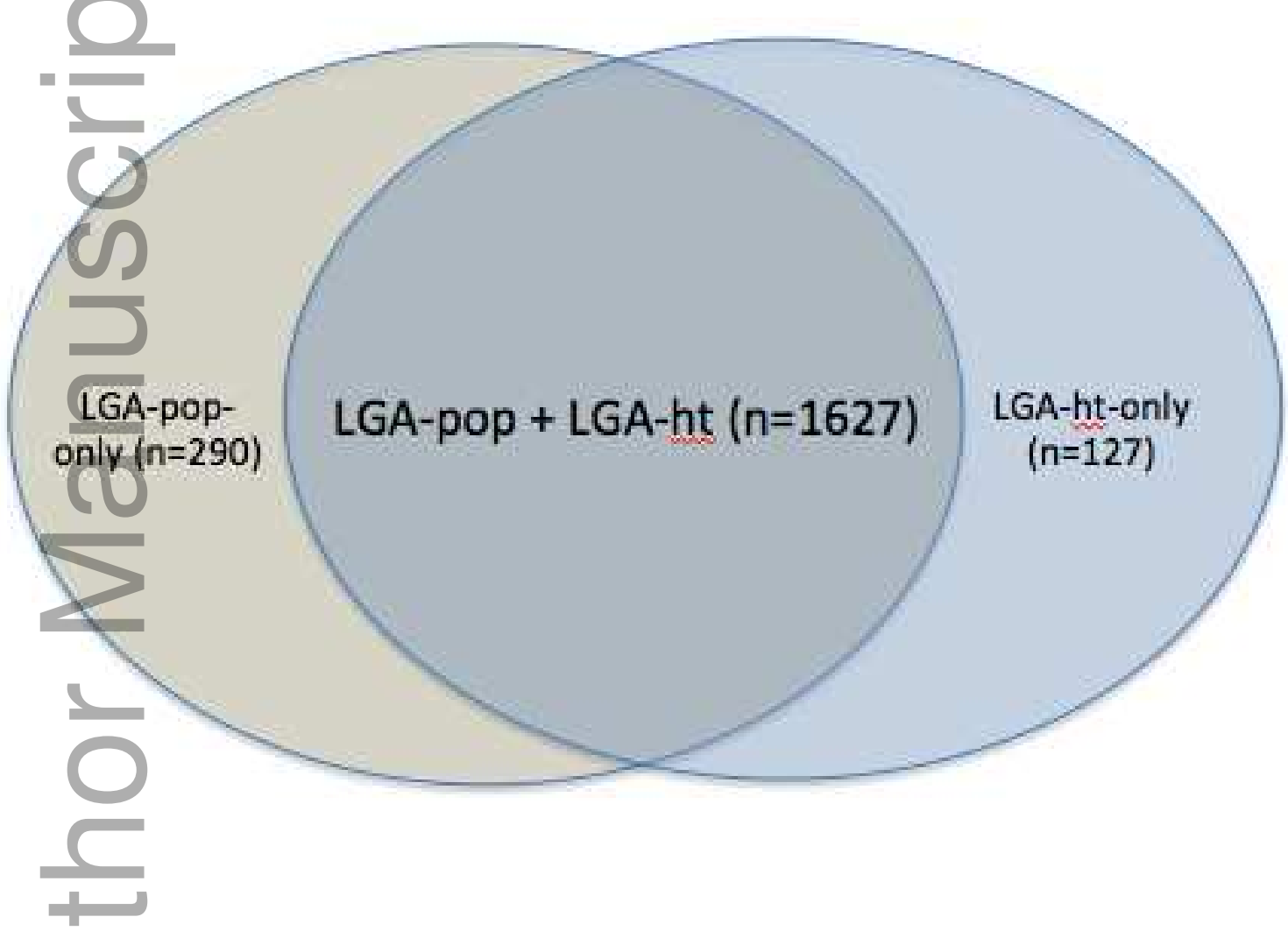

Table I: Comparison between the participants identified by population charts only or height-customised charts only

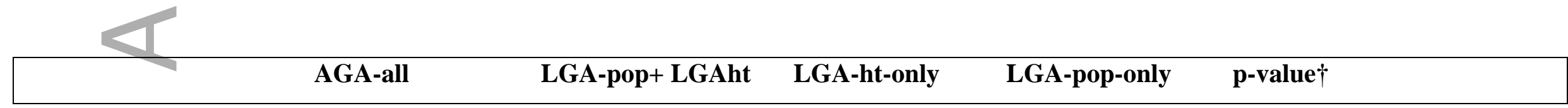




\begin{tabular}{|c|c|c|c|c|c|}
\hline & $(n=35,854)$ & $(n=1627)$ & $(n=127)$ & $(n=290)$ & \\
\hline \multicolumn{6}{|l|}{ Baseline characteristics } \\
\hline Age (years), mean (SD) & $30.0(4.9)$ & $30.3(5.0)$ & $30.0(4.8)$ & $30.3(4.9)$ & 0.70 \\
\hline Height $(\mathrm{cm})$, mean (SD) & $164(7.0)$ & $166(6.6)$ & $156(4.4)$ & $174(4.7)$ & $<0.001$ \\
\hline $\begin{array}{l}\text { Gestation at delivery } \\
\text { (days), mean (SD) }\end{array}$ & $279(8.3)$ & $277(8.9)$ & $277(9.1)$ & $278(8.9)$ & 0.12 \\
\hline $\begin{array}{l}\text { Birthweight (grams), } \\
\text { mean (SD) }\end{array}$ & $3346(413)$ & $4294(335)$ & $4015(276)$ & $4140(276)$ & $<0.001$ \\
\hline \multicolumn{6}{|l|}{ Other delivery outcomes } \\
\hline Emergency CS (\%) & $7121(21.2)$ & $594(42.7)$ & $61(55.5)$ & $73(27.8)$ & $<0.001$ \\
\hline $\begin{array}{l}\text { Instrumental delivery } \\
(\%) \S\end{array}$ & $9,429(35.5)$ & $362(45.4)$ & $23(46.9)$ & $88(46.3)$ & $>0.999$ \\
\hline \multicolumn{6}{|l|}{ Neonatal outcomes } \\
\hline Apgars $<7$ & $661(1.8)$ & $24(1.5)$ & $2(1.6)$ & $0(0.0)$ & 0.09 \\
\hline SCN/NICU admission & $2355(6.6)$ & $177(10.9)$ & $10(7.9)$ & $14(4.8)$ & 0.22 \\
\hline
\end{tabular}

This article is protected by copyright. All rights reserved 


\begin{tabular}{|llllll|}
\hline Shoulder dystocia§ & $348(1.3)$ & $93(11.7)$ & $5(10.2)$ & $8(4.2)$ & 0.07 \\
\hline Maternal outcomes & & & & \\
\hline Massive PPH $>1 \mathrm{~L}$ & $1,750(4.9)$ & $180(11.1)$ & $13(10.2)$ & $17(5.9)$ & 0.11 \\
\hline $3^{\text {rd }} 4^{\text {th }}$ degree tear $\$$ & $994(3.8)$ & $54(6.8)$ & $6(12.2)$ & $11(5.8)$ & 0.12 \\
\hline Regional anaesthesia $\S$ & $11,663(43.9)$ & $425(53.3)$ & $30(61.2)$ & $86(54.7)$ & 0.41 \\
\hline
\end{tabular}

$\dagger$ p-value based on comparison between LGA-ht-only and LGA-pop-only. + Proportion based on total population, excluding women who had an elective caesarean section. § Proportion out of those who had a vaginal delivery.

Table II. Intrapartum caesarean section rate. $\dagger$

\begin{tabular}{|lccc|}
\hline Classification (n) & Number & Rate/100 & Unadjusted Odds Ratio (95\% CI) \\
\hline AGA-all(33661) & 7121 & 21.2 & Reference \\
\hline LGA-pop (1655) & 656 & 40.3 & $2.52(2.27-2.78)$ \\
\hline LGA-ht (1502) & 655 & 43.6 & $2.88(2.60-3.2)$ \\
\hline LGA-ht+LGA-pop (1627) & 594 & 42.7 & $2.77(2.49-3.10)$ \\
\hline LGA-pop-only (290) & 73 & 27.8 & $1.43(0.70-1.88)$ \\
\hline LGA-ht-only (127) & 61 & 55.5 & $4.64(3.22-6.76)$ \\
\hline
\end{tabular}

$\dagger$ Excludes women that had an elective caesarean section.

Figure II. i) Comparison of height-customised and height and weight-customised charts. Number of women identified by height-customised and height and weight-customised (LGA-ht+LGA-ht+wt), height-customised charts only (LGA-ht-only) and height and weight-customised charts

This article is protected by copyright. All rights reserved 
only (LGA-ht+wt). ii) Comparison of height and weight-customised with population charts. Number of women identified by height and weightcustomised and uncustomised charts (LGA-pop + LGA-ht+wt), height and weight-customised charts only (LGA-ht+wt-only) and uncustomised charts only (LGA-pop-only).

i)

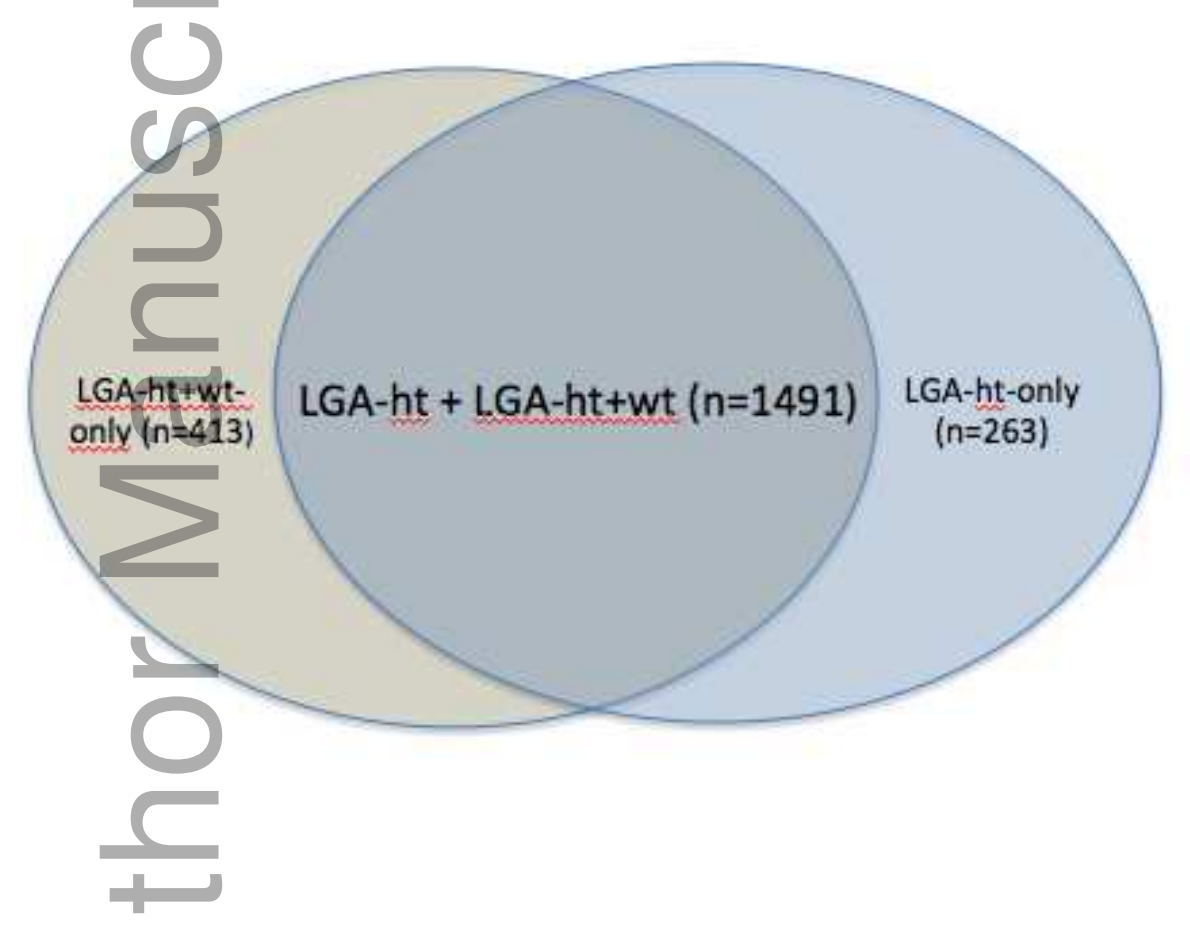

ii)

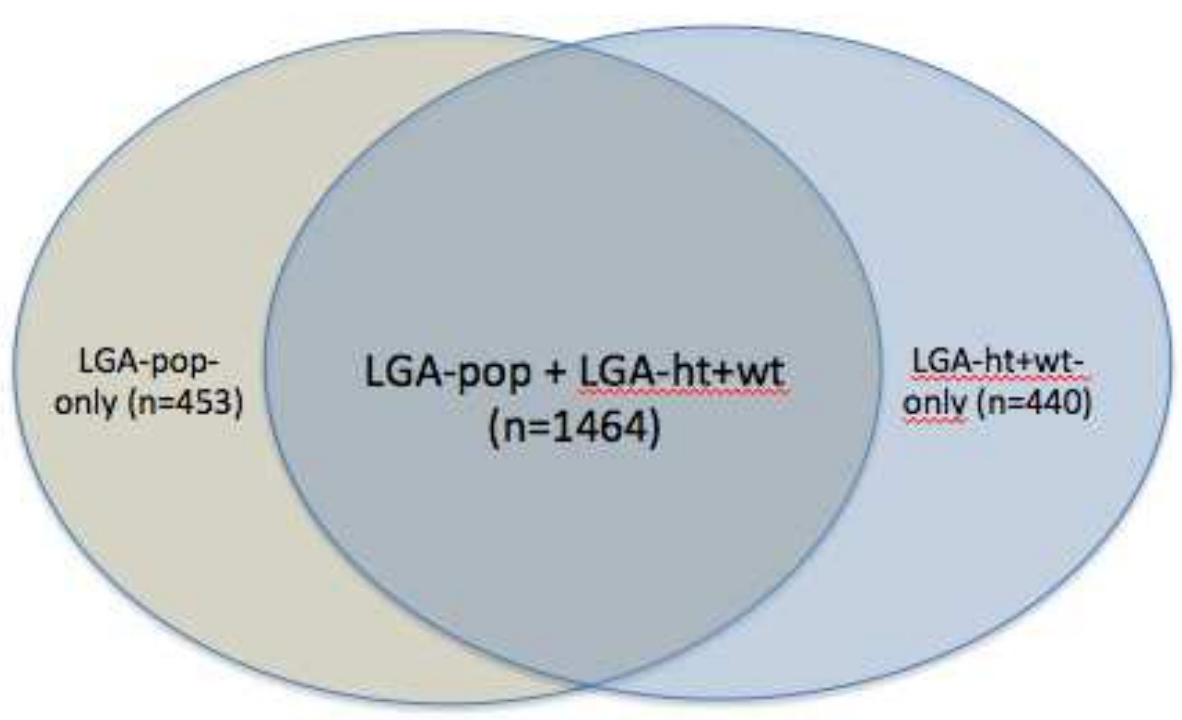

Table III. Comparison between the groups identified by charts customised on height only or charts customised on height and weight only

\begin{tabular}{|ll|}
$\begin{array}{l}\text { Height-customised vs height and weight-customised } \\
\text { charts }\end{array}$ & $\begin{array}{l}\text { Uncustomised vs height and weight-customised } \\
\text { charts }\end{array}$ \\
\hline
\end{tabular}

This article is protected by copyright. All rights reserved 


\begin{tabular}{|c|c|c|c|c|c|c|}
\hline J & $\begin{array}{l}\text { LGA-ht-only } \\
(\mathrm{n}=\mathbf{2 6 3})\end{array}$ & $\begin{array}{l}\text { LGA-ht+wt-only } \\
(n=413)\end{array}$ & p-value & $\begin{array}{l}\text { LGA-pop-only } \\
(n=453)\end{array}$ & $\begin{array}{l}\text { LGA-ht+wt } \\
\text { only }(n=440)\end{array}$ & p-value \\
\hline \multicolumn{7}{|c|}{ Baseline characteristics } \\
\hline $\begin{array}{l}\text { BMI }\left(\mathrm{kg} / \mathrm{m}^{2}\right) \text {, mean } \\
(\mathrm{SD})\end{array}$ & $34.1(6.2)$ & $21.4(21.2)$ & $<0.001$ & $30.6(6.9)$ & $22.0(2.8)$ & $<0.001$ \\
\hline $\begin{array}{l}\text { Gestation at delivery } \\
\text { (days), mean (SD) }\end{array}$ & $275(9.2)$ & $278(8.4)$ & 0.020 & $277(8.9)$ & $277(8.5)$ & 0.90 \\
\hline $\begin{array}{l}\text { Birthweight (grams), } \\
\text { mean (SD) }\end{array}$ & $4144(304)$ & $4001(275)$ & $<0.001$ & $4151(283)$ & $3983(304)$ & $<0.0001$ \\
\hline \multicolumn{7}{|l|}{ Delivery outcomes } \\
\hline Elective CS (\%) & $37(14.1)$ & $35(8.5)$ & 0.022 & $56(12.4)$ & $44(10.0)$ & 0.29 \\
\hline $\begin{array}{l}\text { Vaginal delivery (\%) } \\
\dagger\end{array}$ & $118(44.9)$ & $253(61.3)$ & $<0.001$ & $256(56.5)$ & $250(56.9)$ & 0.93 \\
\hline $\begin{array}{l}\text { Instrumental delivery } \\
(\%) \S\end{array}$ & 55 (46.6) & $101(39.9)$ & 0.224 & $121(47.3)$ & $102(40.8)$ & 0.14 \\
\hline
\end{tabular}

$\dagger$ Proportion of the total population. § Proportion out of those who had a vaginal delivery.

This article is protected by copyright. All rights reserved 
Figure I: Comparison of height-customised charts with uncustomised population charts. Number of women identified by both charts (LGApop+LGA-ht), a population chart only (LGA-pop-only) or height-customised charts only (LGA-ht-only).

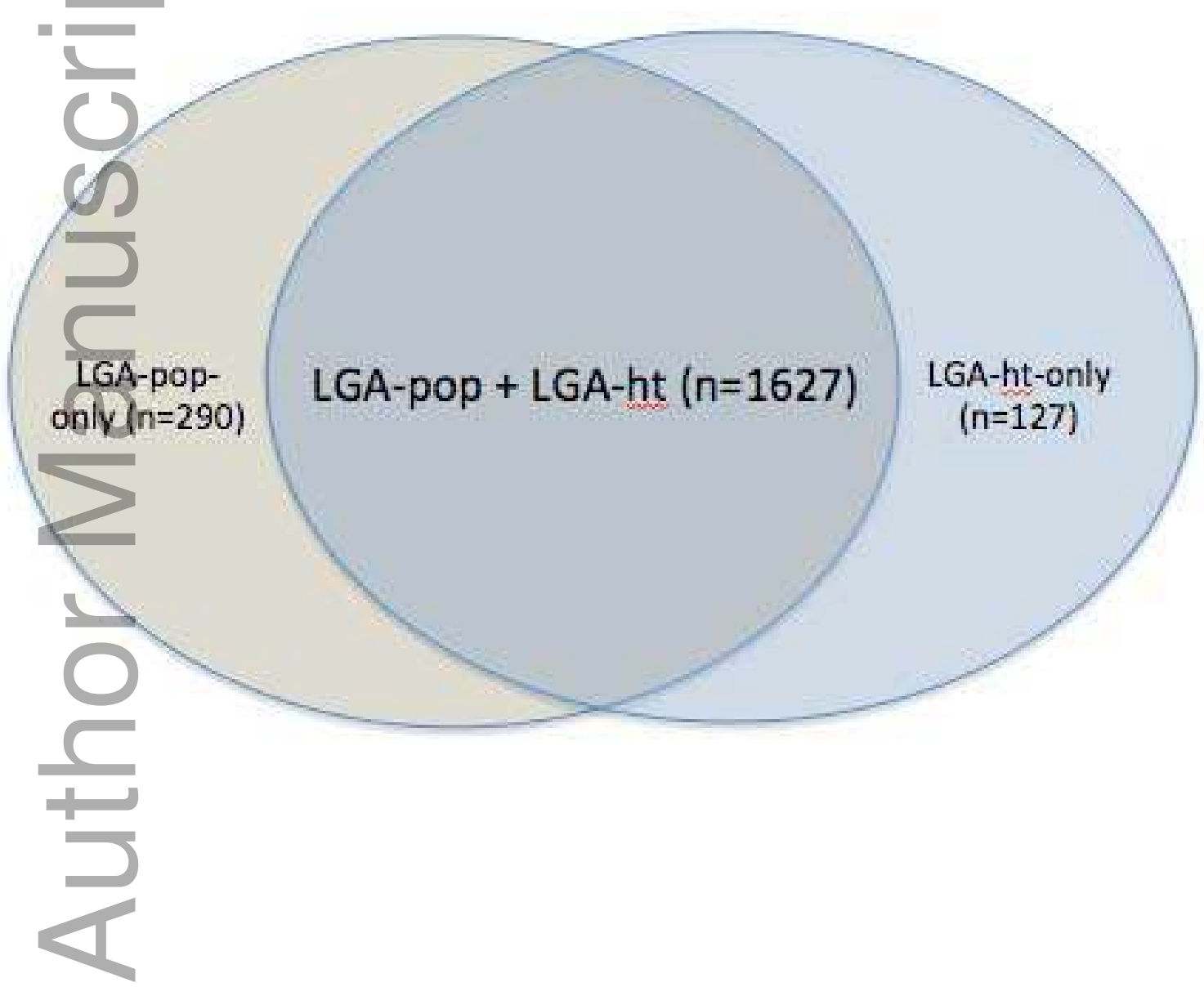

This article is protected by copyright. All rights reserved 
Table I: Comparison between the participants identified by population charts only or height-customised charts only

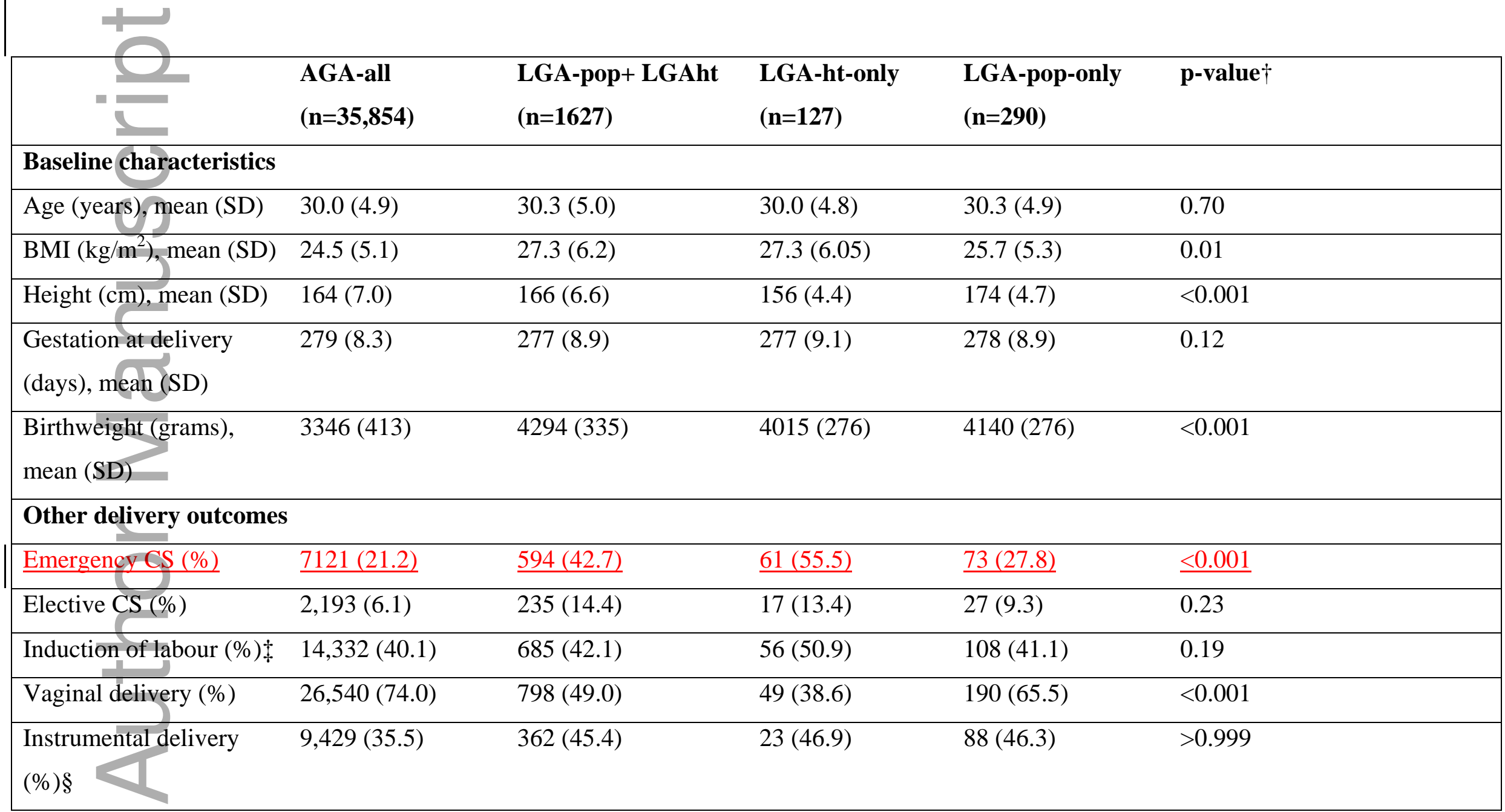




\begin{tabular}{|c|c|c|c|c|c|}
\hline \multicolumn{6}{|l|}{ Neonatal outcomes } \\
\hline Apgars $<7$ & $661(1.8)$ & $24(1.5)$ & $2(1.6)$ & $0(0.0)$ & 0.09 \\
\hline SCN/NICU admission & $235533,499(6.6)$ & $177(10.9)$ & $10(7.9)$ & $14(4.8)$ & 0.22 \\
\hline \multicolumn{6}{|l|}{ Maternal outcomes } \\
\hline Massive $\mathrm{PPH}>1 \mathrm{~L}$ & $1,750(4.9)$ & $180(11.1)$ & $13(10.2)$ & $17(5.9)$ & 0.11 \\
\hline Regional anaesthesia§ & $11,663(43.9)$ & $425(53.3)$ & $30(61.2)$ & $86(54.7)$ & 0.41 \\
\hline
\end{tabular}

$\dagger$ p-value based on comparison between LGA-ht-only and LGA-pop-only. $\$$ Proportion based on total population, excluding women who had an elective caesarean section. § Proportion out of those who had a vaginal delivery.

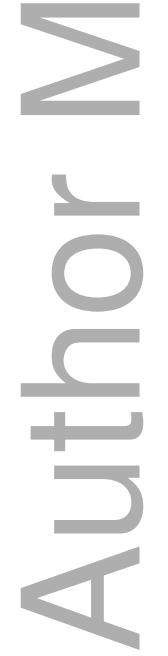

This article is protected by copyright. All rights reserved 
Table II. Intrapartum caesarean section rate. $\dagger$

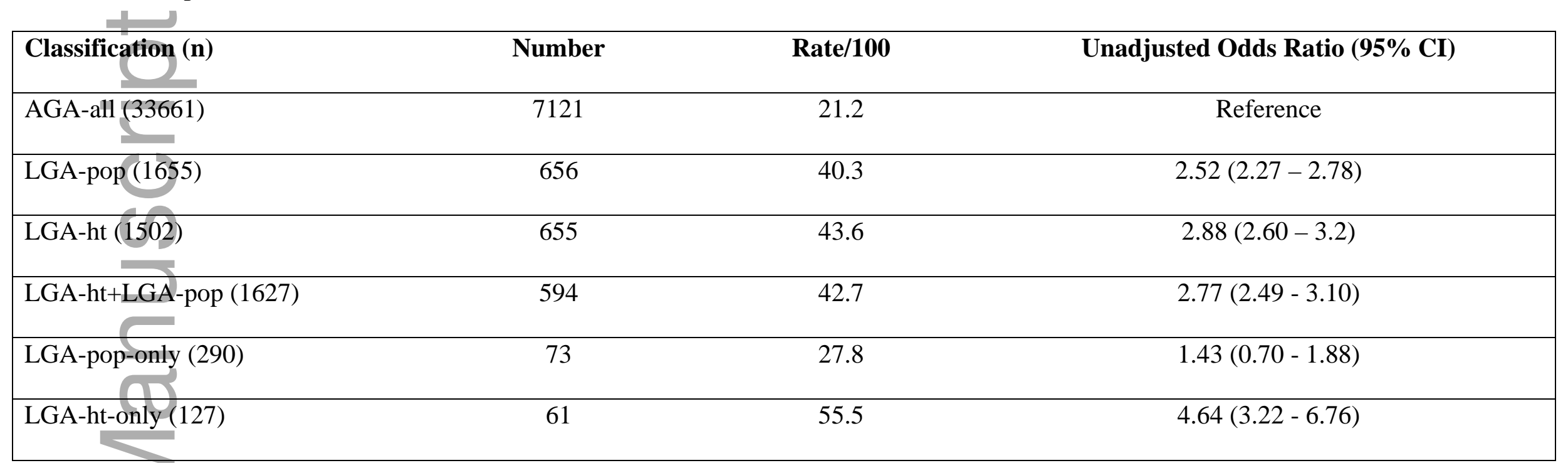

$\dagger$ Excludes women that had an elective caesarean section. 
Figure II. i) Comparison of height-customised and height and weight-customised charts. Number of women identified by height-customised and height and weight-customised (LGA-ht+LGA-ht+wt), height-customised charts only (LGA-ht-only) and height and weight-customised charts only (LGA-ht+wt). ii) Comparison of height and weight-customised with population charts. Number of women identified by height and weightcustomised and uncustomised charts (LGA-pop + LGA-ht+wt), height and weight-customised charts only (LGA-ht+wt-only) and uncustomised charts only (LGA-pop-only).

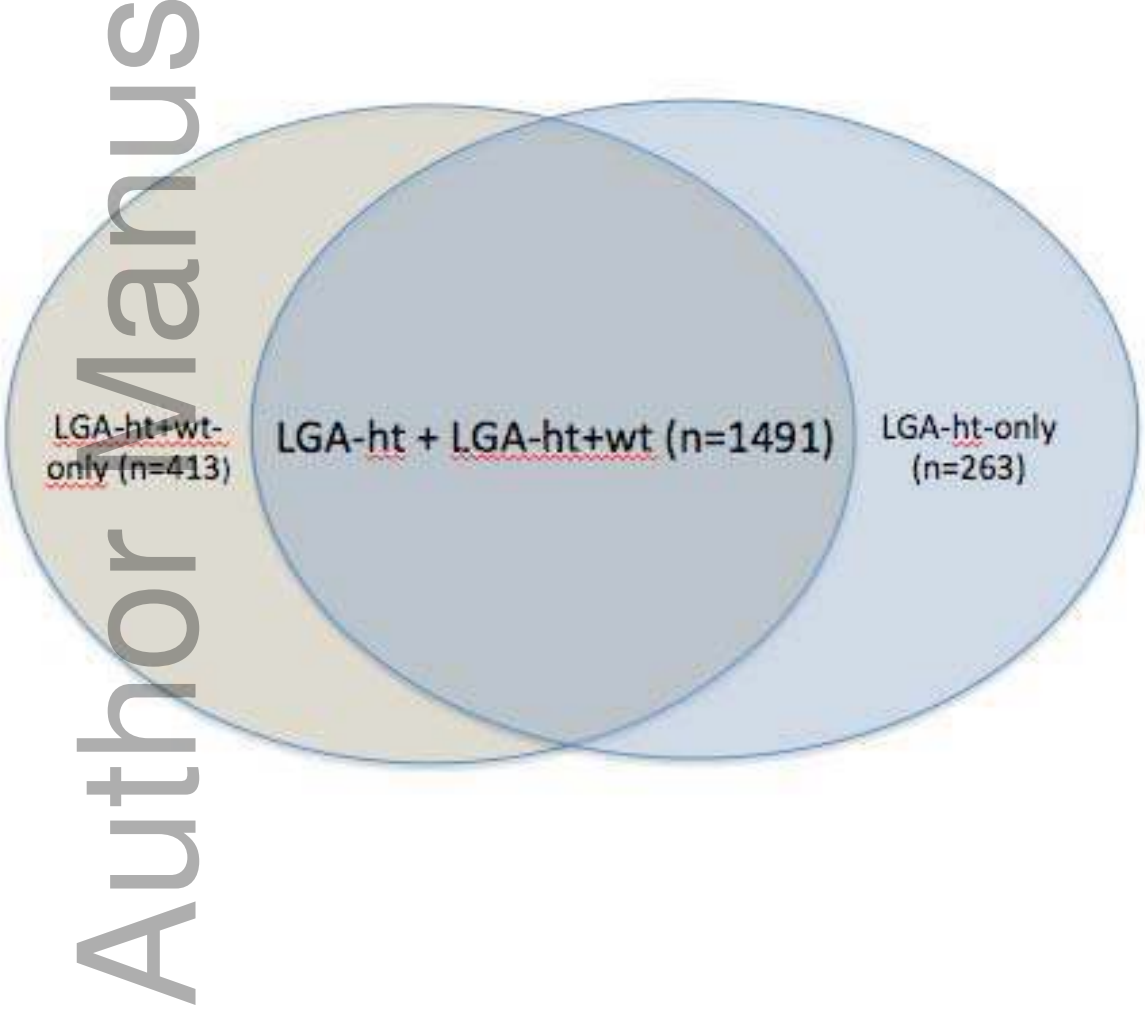

ii)

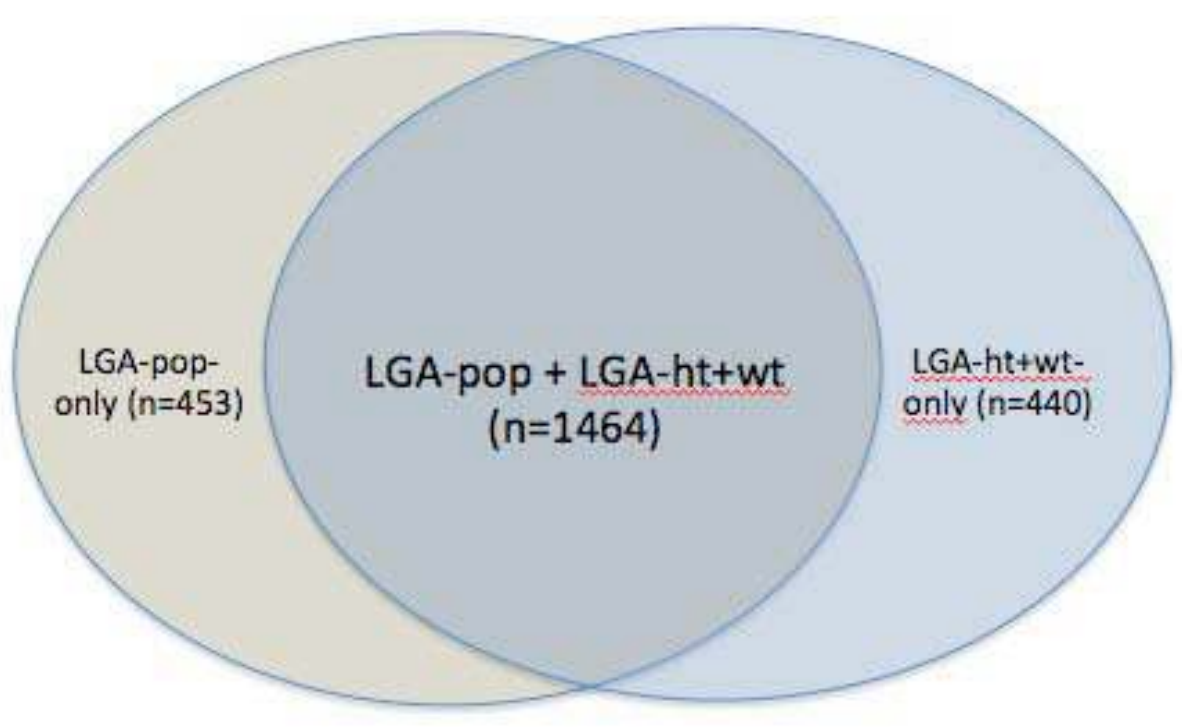

This article is protected by copyright. All rights reserved 
Table III. Comparison between the groups identified by charts customised on height only or charts customised on height and weight only

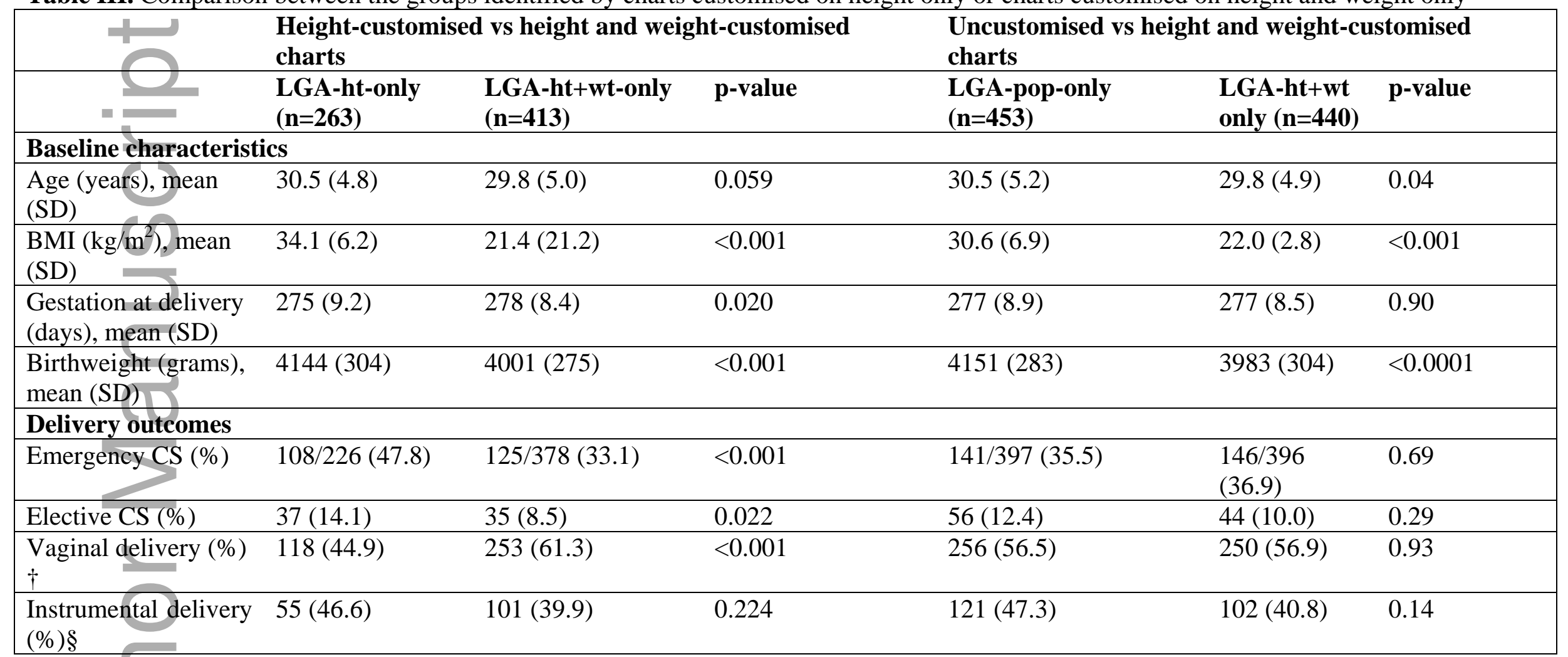

$\dagger$ Proportion of the total population. § Proportion out of those who had a vaginal delivery. 


\section{University Library}

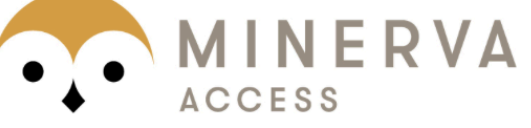

A gateway to Melbourne's research publications

Minerva Access is the Institutional Repository of The University of Melbourne

Author/s:

Pritchard, N;Lindquist, A;Hiscock, R;Diksha, P;Walker, SP;Permezel, M

Title:

Customised growth charts in large-for-gestational-age infants and the association with emergency caesarean section rate

Date:

2019-06-01

Citation:

Pritchard, N., Lindquist, A., Hiscock, R., Diksha, P., Walker, S. P. \& Permezel, M. (2019). Customised growth charts in large-for-gestational-age infants and the association with emergency caesarean section rate. AUSTRALIAN \& NEW ZEALAND JOURNAL OF OBSTETRICS \& GYNAECOLOGY, 59 (3), pp.380-386. https://doi.org/10.1111/ajo.12868.

Persistent Link:

http://hdl.handle.net/11343/284346 